\title{
Optimized Stepwise Synthesis of the API Liraglutide Using BAL Resin and Pseudoprolines
}

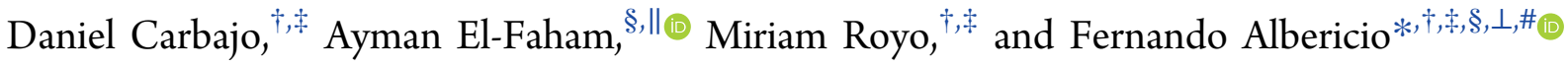 \\ ${ }^{\dagger}$ CIBER-BBN, Networking Centre on Bioengineering, Biomaterials and Nanomedicine, Barcelona Science Park, 08028 Barcelona, \\ Spain \\ ${ }^{\ddagger}$ Institute of Advanced Chemistry of Catalonia (IQAC-CSIC), Spanish National Research Council (CSIC), 08034 Barcelona, Spain \\ ${ }^{\S}$ Department of Chemistry, College of Science, King Saud University, P.O. Box 2455, Riyadh 11451, Saudi Arabia \\ "Department of Chemistry, Faculty of Science, Alexandria University, P.O. Box 426, Alexandria 21321, Egypt \\ ${ }^{\perp}$ Department of Organic Chemistry, University of Barcelona, 08028 Barcelona, Spain \\ ${ }^{\#}$ School of Chemistry and Physics, University of KwaZulu-Natal, Durban 4001, South Africa
}

Supporting Information

ABSTRACT: The number of peptide-based active pharmaceutical ingredients (APIs) has increased enormously in recent years. Furthermore, the emerging new peptide drug candidates are more complex and larger. For the industrial solid-phase synthesis of C-carboxylic acid peptides, the two main resins available, Wang and chlorotrityl chloride (CTC), have a number of drawbacks. In this context, resins that form an amide bond with the first amino acid are more robust than Wang and CTC resins. Here, we address the use of the backbone (BAL) resin for the synthesis of the peptide liraglutide. The BAL resin, in conjunction with the use of

pseudoprolines to avoid aggregation, allows the stepwise solid-phase synthesis of this API in excellent purity and yield.

\section{INTRODUCTION}

Recent years have witnessed a significant increase in the number of peptides based on active pharmaceutical ingredients (APIs). ${ }^{1}$ Furthermore, during the last decade, peptides on the market have evolved from being small and linear, with approximately 10 amino acids, to being much more complex. ${ }^{2}$ This has led to an increasing number of cyclic, longer (20-40 amino acids) peptides receiving approval from regulatory agencies. Thus, these organisms are increasingly approving cyclic peptides, longer peptides (20-40 amino acids), and peptides containing fatty acids. ${ }^{3}$

Industrially, all of these peptides are prepared at a multikilogram scale using the solid-phase peptide synthesis (SPPS) strategy first developed by Merrifield in the early 1960s. ${ }^{4}$ The idea behind this approach is straightforward, namely the use of a polymeric protecting group for one of the functions present in the amino acid. The elongation of the peptide chain is then carried out by successive introduction of the amino acid with the other function temporally protected, removal of the temporal protecting group, and repetition of the sequence. As the presence of the polymer makes the growing peptide chain insoluble in the reaction medium, the work-up is easily carried out by simple filtration and washings. This allows the use of excesses of the incoming protected amino acid (3-5 equiv in research; 1.5 equiv in production) and of the deprotection

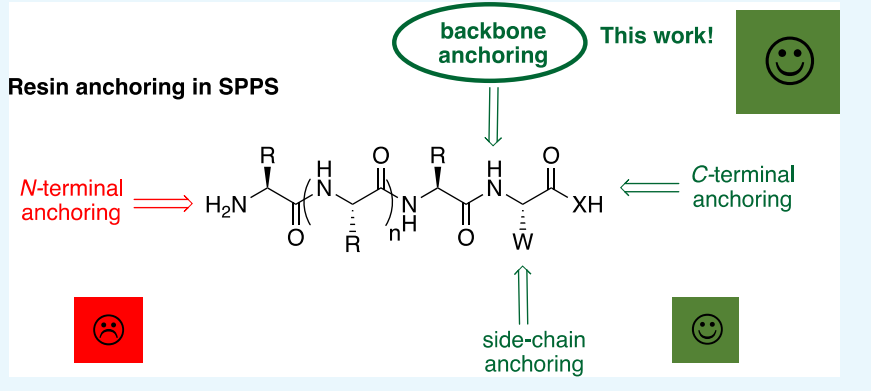

reagent, thus making the reaction almost quantitative in many of the cases.

Peptides are synthesized from $\mathrm{C}$ to $\mathrm{N}$, which implies that the carboxylic group of the first amino acid is protected with the polymeric support, and the rest of amino acids are introduced through the carboxylic group with a protected $\alpha$-amino function and the side chain if required. The $\mathrm{C}-\mathrm{N}$ strategy was attempted by Merrifield ${ }^{5}$ and later by our group, ${ }^{6}$ but it is not practical because of a large number of associated drawbacks, related mainly to poor coupling yields, the formation of diketopiperazines (DKP) with the termination of the growing chain, and of oxazolones with the concomitant racemization.

Most research and industrial peptides require either a carboxamide or a carboxylic acid at the extreme C-terminal. Rink Amide, ${ }^{7}$ PAL, $^{8}$ and Sieber ${ }^{9}$ are the most widely used resins when carboxamide peptides are desired, whereas Wang ${ }^{10}$ and chlorotrityl chloride (CTC) ${ }^{11}$ are the resins of choice for carboxylic acids. The precursors of cyclic peptides are also synthesized as carboxylic acids. The CTC resin is excellent for the synthesis of small-medium molecules, but the synthesis of longer peptides can be jeopardized by the instability of the

Received: April 5, 2019

Accepted: April 18, 2019

Published: May 17, 2019 
CTC-ester bond. ${ }^{12}$ This limiting feature gains relevance in an industrial context. Although the Wang resin is more stable, the introduction of the first amino acid is not straightforward, and the presence of free hydroxyl groups can lead to the presence of peptides with deletion peptides as impurities in the final product. ${ }^{13}$ Furthermore, the Wang resin is susceptible to forming DKP after the removal of the Fmoc group of the second residue.

Sieber and CTC resins allow the release of peptides using a low concentration of trifluoroacetic acid (TFA) (4 and 1-2\%, respectively), which is suitable for the preparation of protected peptides. In contrast, the other resins require high concentrations of TFA.

In terms of robustness, the preparation of amide peptides is preferred, due to the higher stability of the amide against the ester (DKP formation takes place with esters and not with amides $)^{14}$ and the greater ease of formation of the amide bond vs the ester. Thus, the synthesis of Asn/Gln C-terminal peptides is best carried out using carboxamide resins and by introducing the first amino acid in the form of Fmoc-Asp/Glu$\mathrm{O} t \mathrm{Bu}$ through the side chain. ${ }^{15}$ Similarly, Lys can be anchored through the $\varepsilon$-amino function. ${ }^{16}$ Other trifunctional amino acids can be also anchored through the side chain. ${ }^{17}$ In all of these cases and for the preparation of $\mathrm{C}$-acid peptides, the $\alpha$ carboxylic group will be protected in the form of a $t \mathrm{Bu}$ ester, which is removed during global deprotection and cleavage.

Less attention has been paid to starting the synthesis through the backbone. This approach can be carried out using formyl trialkoxyphenyl (BAL) resin. ${ }^{18}$ This support allows the introduction of the first amino C-terminal amino acid through the $\alpha$-amino by a reductive amination, rendering a secondary amine, which is in turn acylated by the second protected amino acid for the continuation of the synthesis. It is important to highlight that using the BAL strategy, the anchoring of the growing peptide resin is also through an amide bond and that the treatment of the peptide-BAL resin with TFA releases a linear peptide. The main drawback of the BAL resin is the difficulty to acetylate the second amino acid of the secondary amino acid. However, this acylation is performed safely when the first amino acid is not hindered, such as for Ala, Leu, and Phe, and in the case of Gly. Figure 1 shows the four tentative possibilities of starting SPPS.

As the size of the peptide sequence increases, the probability of intra- and interchain interactions rises considerably, which is the main cause for the appearance of a large number of deletion peptides as side products. ${ }^{19}$ Many approaches have

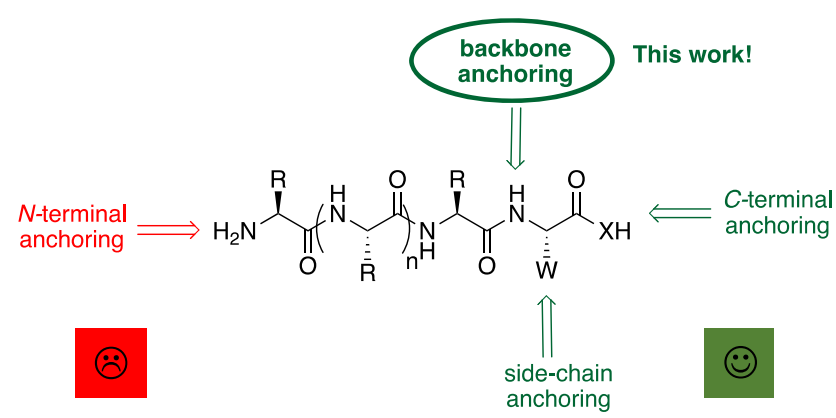

Figure 1. Options for resin anchoring in solid-phase peptide synthesis: C-terminal anchoring (most used); side-chain anchoring (very useful for trifunctional first amino acids); N-terminal anchoring (not recommended); backbone anchoring (this work). been developed to reduce chain interactions. ${ }^{19}$ However, when residues of Ser and Thr are present in the peptide sequence, the use of pseudoprolines ( $\psi$-Pros) is probably the best approach. ${ }^{20} \psi$-Pro is a backbone amide-protecting group built with the hydroxyl group of Ser and Thr, and it has a structure of dimethyloxazolidine, which allows the release of the Ser and Thr under TFA treatment. The five-member ring is very similar to that of Pro, thus disrupting the hydrogen bond on the backbone and destabilizing the $\beta$-sheet folding of peptides, processes that induce aggregation.

Within this project, we aimed to demonstrate the feasibility of backbone anchoring using the BAL resin in the synthesis of a difficult and long C-terminal carboxylic acid peptide, thus avoiding the disadvantages presented by both Wang and CTC resins. For the synthesis of C-terminal carboxylic acid peptides, the carboxylic group of the first amino acid was protected in the form of a $t \mathrm{Bu}$ ester. Then, during the TFA cleavage treatment, the traceless $\mathrm{BAL}$ resin would release the peptide as a C-terminal carboxylic acid (Figure 2).

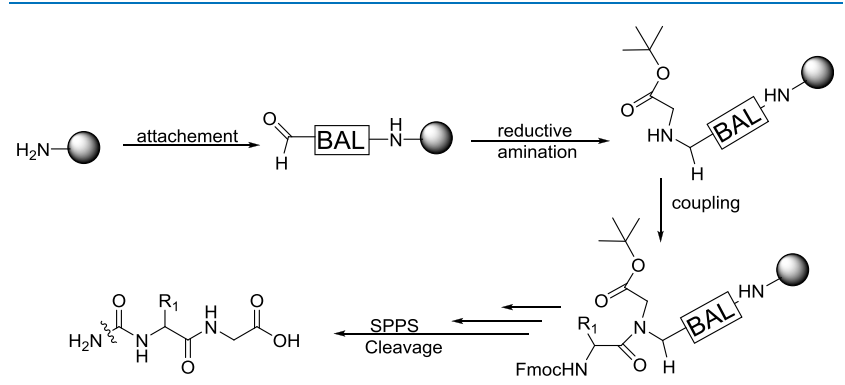

Figure 2. General example of the BAL linker use.

To evaluate our strategy, we chose the API liraglutide, which is currently a blockbuster sold under the name of Victoza. ${ }^{21}$ Liraglutide has a linear sequence of 31 amino acids that is branched at the $\mathrm{Lys}^{27}$ side chain with a palmitoyl- $\gamma$-Glu moiety (Figure 3).

H-His ${ }^{8} \cdot$ Ala-Glu-Gly-Thr-Phe-Thr-Ser-Asp-Val-Ser-Ser-Tyr-Leu

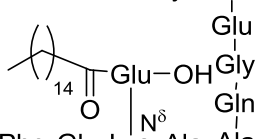

HO-Gly ${ }^{38}$-Arg-Gly-Arg-Val-Leu-Trp-Ala-Ile-Phe-Glu-Lys-Ala-Ala

Figure 3. Sequence of liraglutide.

It is important to highlight that a 31 -amino acid peptide such as liraglutide could represent the limit for being synthesized in a stepwise mode (amino acid after amino acid). For peptides around this size or longer, a hybrid (solidphase/solution) approach should be more appropriate. ${ }^{22,23}$

\section{RESULTS}

As we were targeting a long linear peptide, liraglutide, we used the aminomethyl-ChemMatrix (CM) resin as support for SPPS. This full polyethylene glycol support has been developed for long and difficult peptides, thus making it the most suitable resin for the synthesis of this 31-amino acid peptide. $^{24}$ This resin is compatible with the introduction of any of the linkers available and also with the Fmoc/tBu strategy.

First, the BAL linker was safely anchored to the $\mathrm{CM}$ resin using DIC/OxymaPure as the coupling reagent cocktail for $4 \mathrm{~h}$ (Figure 4). Both the ninhydrin and the aldehyde test 


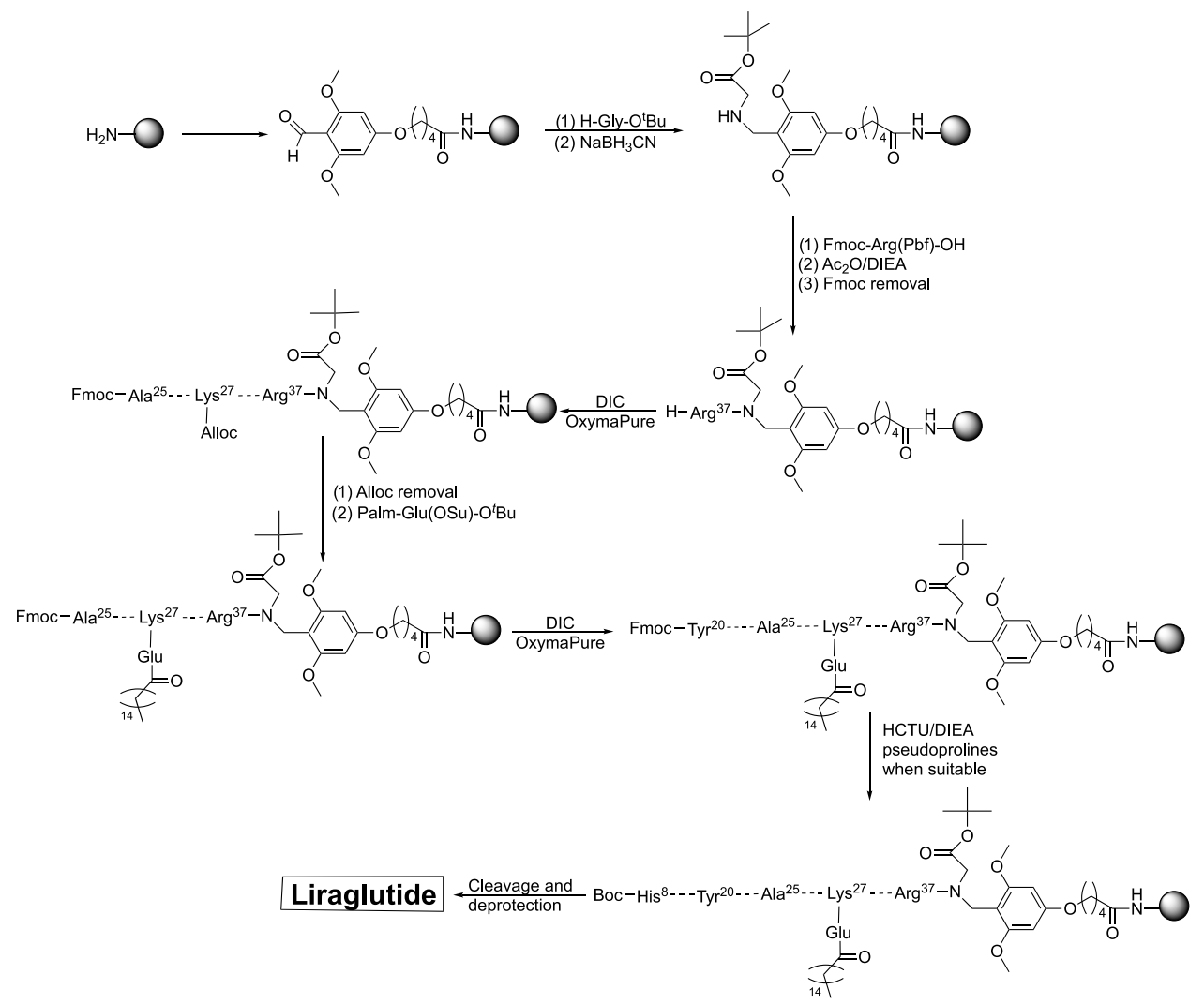

Figure 4. Initial design of the synthetic scheme for liraglutide.
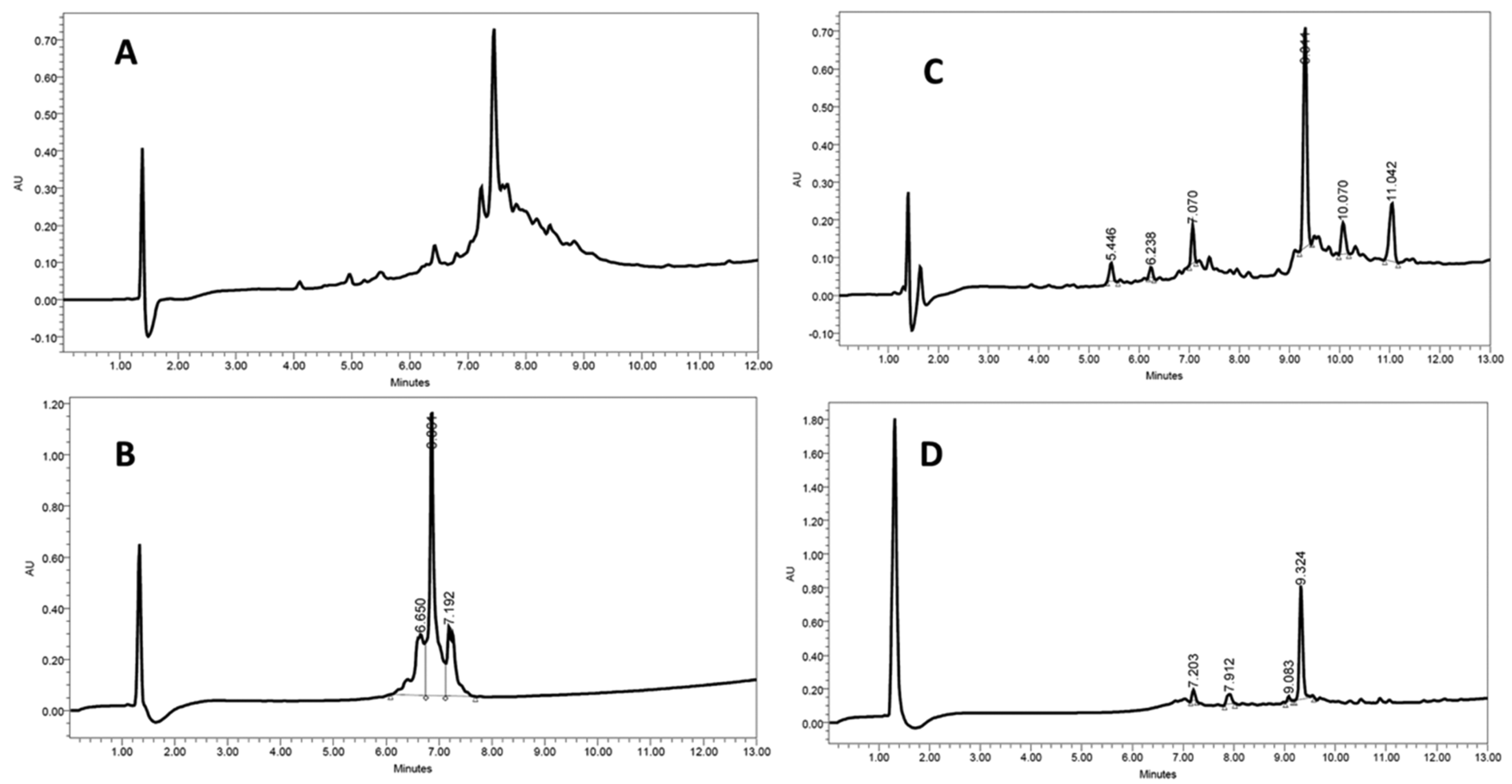

Figure 5. HPLC trace of the crude peptide under different conditions. (A) HCTU/DIEA, no pseudoprolines; (B) pseudoprolines for Val ${ }^{17}$-Ser ${ }^{18}$; (C) pseudoprolines for $\mathrm{Phe}^{13}-\mathrm{Thr}^{14}$ and $\mathrm{Val}^{17}-\mathrm{Ser}^{18}$; and (D) pseudoprolines for $\mathrm{Gly}^{11}-\mathrm{Thr}^{12}, \mathrm{Phe}^{13}-\mathrm{Thr}^{14}, \mathrm{and} \mathrm{Val}^{17}-\mathrm{Ser}^{18}$. (A, B) $10-100 \%$ $\mathrm{H}_{2} \mathrm{O}: \mathrm{ACN}$ (0.1\% TFA in $13 \mathrm{~min}$ ), $220 \mathrm{~nm}$; (C, D) 5-100\% $\mathrm{H}_{2} \mathrm{O}: \mathrm{ACN}$ (0.1\% TFA in $13 \mathrm{~min}$ ), $220 \mathrm{~nm}$.

confirmed that the linker was effectively anchored. After that, reductive amination was used to introduce the $\mathrm{C}$-terminalprotected $\mathrm{H}-\mathrm{Gly}-\mathrm{O} t \mathrm{Bu}$, using $\mathrm{NaBH}_{3} \mathrm{CN}$ as the reducing agent. The next amino acid to be coupled, Fmoc-Arg(Pbf)-OH, was initially introduced in $90 \mathrm{~min}$ using DIC/OxymaPure. However, the chloranyl test showed that the reaction was incomplete. $^{25}$ Recoupling under the same conditions led to coupling completion, as confirmed by Fmoc determination. 
Table 1. Purities Obtained Using the Different Methods for Liraglutide Sequence Completion ${ }^{a}$

\begin{tabular}{|c|c|c|c|}
\hline \# & pseudoprolines & C. reagents & purity (\%) \\
\hline (not shown) & none & DIC/Oxyma & $<5$ \\
\hline A & none & HCTU/DIEA & 14 \\
\hline B & Val $^{17}-$ Ser $^{18}$ & HCTU/DIEA & 55 \\
\hline $\mathrm{C}$ & $\mathrm{Phe}^{13}-\mathrm{Thr}^{14}$ and $\mathrm{Val}^{17}-\mathrm{Ser}^{18}$ & HCTU/DIEA & 71 \\
\hline $\mathrm{D}$ & $\mathrm{Gly}^{11}-\mathrm{Thr}^{12}, \mathrm{Phe}^{13}-\mathrm{Thr}^{14}$ and $\mathrm{Val}^{17}-\mathrm{Ser}^{18}$ & HCTU/DIEA & 91 \\
\hline
\end{tabular}

${ }^{a}$ HPLC traces are shown in Figure 5.

Before continuing the synthesis, acylation with $\mathrm{Ac}_{2} \mathrm{O} /$ diisopropyl ethylamine (DIEA) in dimethylformamide (DMF) is highly recommended, to prevent further acylation of those non-arginylated reactive groups that would lead to Arg-deletion peptides.

The coupling of the next 20 amino acids was carried out with DIC/OxymaPure, and the performance was checked by the ninhydrin test. ${ }^{26}$ To assess the correct progress of the peptide, high performance liquid chromatography (HPLC) analyses of the peptide from minicleavages (approx. $5 \mathrm{mg}$ of resin) were performed every six amino acids.

Initially, the synthesis was carried out without the recourse of $\psi$-Pro. Recouplings were established when incomplete couplings were detected (ninhydrin positive), but the main problems arose during the introduction of the last 10 amino acids, because they required repetitive recouplings. We opted to explore the use of various coupling cocktails for the introduction of amino acids 8-18 (N-terminal) of the sequence. AA/HCTU/DIEA (3 equiv) showed the best results, without the need of recoupling. Nevertheless, the purity continued to be unsatisfactory (Figure 5A).

The sequence of liraglutide contains pairs of amino acids, namely, Gly ${ }^{11}-\mathrm{Thr}^{12}$, $\mathrm{Phe}^{13}-\mathrm{Thr}^{14}$, and $\mathrm{Val}^{17}-\mathrm{Ser}^{18}$, which are suitable to be introduced as $\psi$-Pros in the N-terminal part of the peptide. As such, we explored their coupling as $\psi$-Pros instead of individual Fmoc-amino acids. When Fmoc-L-Val-LSer[ $\psi$-(Me,Me)Pro]-OH was used for the coupling of $\mathrm{Val}^{9}$ $\mathrm{Ser}^{10}$, the desired product was obtained with much greater quality (Figure 5B). However, the impurities were very close to the main peak, thus hindering the purification step. The presence of these impurities close to the target was also reduced when the $\mathrm{Phe}^{13}-\mathrm{Thr}^{14}$ pair was also introduced as $\psi$ Pro (Figure 5C). When the three $\psi$-Pros were used, high purity was achieved (Figure 5D). Of note, the impurities that were difficult to remove during purification were negligible using this approach. In addition, the overall time required for the synthesis was reduced (Table 1).

As stated initially, liraglutide is branched at the $\mathrm{Lys}^{27}$ side chain with a palmitoyl- $\gamma$-Glu moiety. We expected the presence of this long aliphatic chain to hinder the elongation of the peptidic backbone, and so the introduction point was studied in depth. The $\mathrm{Lys}^{27}$ residue was introduced as FmocLys(Alloc)-OH, thus allowing us to orthogonally remove the $N^{\varepsilon}$-protecting group and selectively attach the Palm moiety. Initially, we attempted this introduction as the last step of the synthesis, just before the final cleavage, by using Palm$\mathrm{Glu}(\mathrm{OSu})-\mathrm{O} t \mathrm{Bu} / \mathrm{DIEA}(5 / 10$ equiv). However, no reaction was detected and only the starting material was recovered. This was not surprising because, in our experience, the peptide has a great tendency to aggregate during the introduction of the last 10 residues. We therefore decided to focus on the amino acids that were next to $\mathrm{Lys}^{27}$, whose sequence was -Gln(Trt)-AlaAla-Lys $(\mathrm{X})-\mathrm{Glu}(\mathrm{O} t \mathrm{Bu})$-. Although the intuitive point for the incorporation of the Palm moiety could be thought to be just after the introduction of Fmoc-Lys ${ }^{27}$ (Alloc)-OH, it is well known that the $\varepsilon-\mathrm{NH}_{2}$ of the Lys side chain causes the removal of the Fmoc of the $\alpha$-amino after Alloc removal. As it has been described that this premature and undesirable Fmoc removal can also take place on one or even on two amino acids after the Lys residue, ${ }^{27}$ we attempted to introduce the Palm moiety after the coupling of $\mathrm{Gln}^{24}(\mathrm{Trt})$. However, and although the reaction took place, the conversion was not quantitative. Furthermore, given the price of the commercial Palm$\mathrm{Glu}(\mathrm{OSu})-\mathrm{O} t \mathrm{Bu}$, we decided to optimize its introduction. In this regard, we attempted to introduce the Palm moiety after the introduction of the two Ala residues. In both cases, the reaction evolved slowly, but reached completion with no secondary reactions. As the removal of the Alloc group is safer when further away from Lys, for practical reasons, this group was removed after the second Ala in the final liraglutide synthesis. The presence of this large aliphatic side chain had no significant influence on the coupling efficiency, and so the peptide elongation was performed without further issues but did require the presence of the three $\psi$-Pros.

Once the peptide sequence was completed, the resin was extensively washed with $\mathrm{MeOH}$ and then treated with TFA/ $\mathrm{H}_{2} \mathrm{O} / \mathrm{TIS}$ (94:3:3) for $4 \mathrm{~h}$. After precipitation, the peptide crude was analyzed, showing outstanding purity (84\%) and almost quantitative yield (Figure 6). Of note, no important impurities were found close to the target peptide.

The peptide was finally purified by semipreparative HPLC, rendering liraglutide (final yield, 69\%). The identity was further confirmed by MS (electrospray and MALDI-TOF). Finally, characterization coelution in HPLC with commercial liraglutide validated the identity of our synthetic compound.

\section{DISCUSSION}

In conclusion, the preparation of peptides by SPPS can be initiated not only by anchoring the C-terminal carboxylic group to the corresponding resin but also by backbone anchoring. This is particularly relevant in the synthesis of Ccarboxylic acid peptides, because the two most popular resins available, namely CTC and Wang, show several important drawbacks. The BAL resin forms an amide bond with the first amino acid, which is stable throughout the synthetic process, showing no release of the peptide from the resin.

The stepwise synthesis of medium-large peptides is often jeopardized by intra- and interchain interactions that lead to aggregations. However, our results show that these can be minimized by the introduction of $\psi$-Pros when Ser and Thr residues are present in the difficult part of the sequence.

The excellent synthesis of the important commercial peptide liraglutide using the $\mathrm{BAL}-\mathrm{CM}$ resin and $\psi$-Pros has exemplified the robustness of SPPS for the synthesis of large and complex peptides. ${ }^{28}$ 

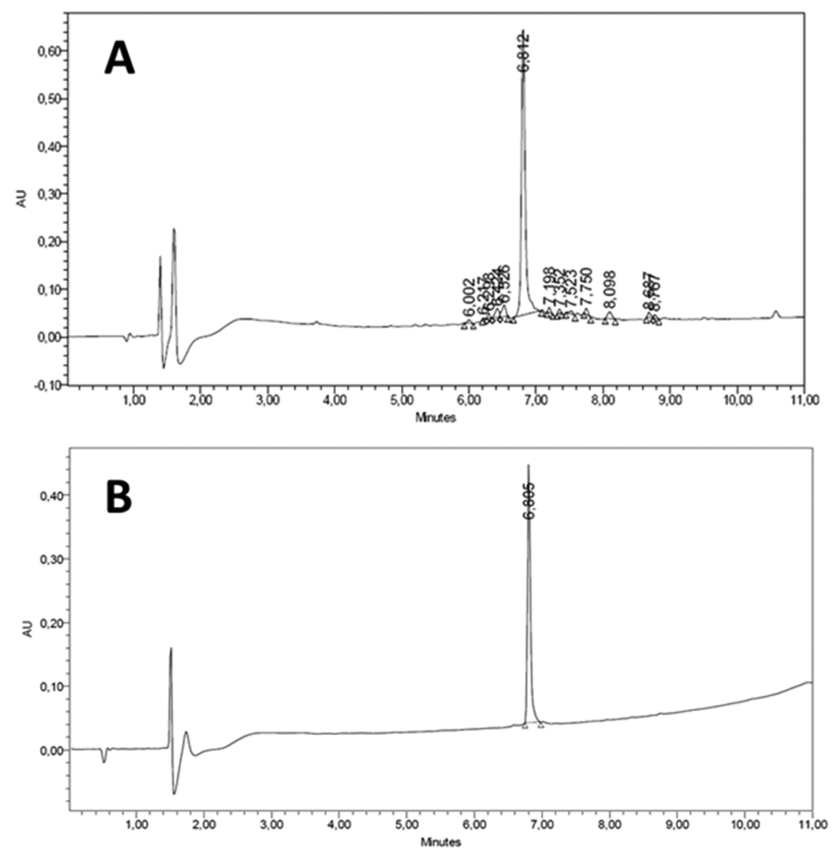

Figure 6. HPLC trace of final liraglutide (A) before purification and (B) after purification $(5-100 \% \mathrm{ACN}(0.1 \% \mathrm{TFA})$ in $10 \mathrm{~min}, 220$ $\mathrm{nm}$ ).

\section{MATERIALS AND METHODS}

Protected amino acids and Palm-Glu(OSu)-OtBu were supplied by Iris Biotech (Marktredwitz, Germany). The BAL linker was purchased from Novabiochem (Darmstadt, Germany). The aminomethyl ChemMatrix resin was provided by ChemMatrix Innovation. Solvents for peptide synthesis and the RP-HPLC equipment were obtained from Scharlau (Barcelona, Spain). Trifluoroacetic acid was supplied by Fluorochem (Derbyshire, United Kingdom). OxymaPure was a gift from Luxembourg Biotech. Other chemicals were obtained from Aldrich (Milwaukee, WI) and were of the highest purity commercially available. All commercial reagents and solvents were used as received.

Analytical RP-HPLC characterization was performed using Waters Alliance 2695 (Milford, MA) chromatography systems with either a reverse-phase Symmetry $C_{18}\left(150 \times 4.6 \mathrm{~mm}^{2}\right) 5$ $\mu \mathrm{m}$ column or $5 \mu \mathrm{m}$ XBridge BEH $C_{18}\left(150 \times 3.5 \mathrm{~mm}^{2}\right)$ equipped with a Waters 995 (detection performed at $220 \mathrm{~nm}$ ) photodiode array detector and ESI-MS Waters Micromass ZQ.

Matrix-assisted laser desorption/ionization mass spectra were recorded on a MALDI Voyager DE RP time-of flight (TOF) spectrometer (Applied Biosystems, Framingham). DHB was used as a matrix and was purchased from Aldrich.

Amino Acids Used. Fmoc-Arg(Pbf)-OH; Fmoc-Gly-OH; Fmoc-Val-OH; Fmoc-Leu-OH; Fmoc-Trp(Boc)-OH; FmocAla-OH; Fmoc-Ile-OH; Fmoc-Phe-OH; Fmoc-Glu $(t \mathrm{Bu})-\mathrm{OH}$; Fmoc-Lys(Alloc); Fmoc-Gln(Trt)-OH; Fmoc-Tyr( $t \mathrm{Bu})-\mathrm{OH}$; Fmoc-Ser $(t \mathrm{Bu})-\mathrm{OH}$; Fmoc-Asp $(t \mathrm{Bu})-\mathrm{OH}$; Boc-His(Trt)-OH; Fmoc-Gly-Thr[ $\psi(\mathrm{Me}, \mathrm{Me}) \mathrm{Pro}]-\mathrm{OH} ; \quad$ Fmoc-Phe-Thr[ $\psi$ (Me,Me)Pro]-OH; Fmoc-Val-Ser[ $\psi(\mathrm{Me}, \mathrm{Me})$ Pro]-OH; Palm$\mathrm{Glu}(\mathrm{OSu})-\mathrm{O} t \mathrm{Bu}$; and $\mathrm{H}-\mathrm{Gly}-\mathrm{O} t \mathrm{Bu}$.

General Solid-Phase Peptide Synthesis Procedures. Peptide syntheses were performed manually in a polypropylene syringe fitted with a polyethylene porous disc. Solvents and soluble reagents were removed by suction. Washings between deprotection, coupling, and subsequent deprotection steps were carried out with DMF $(5 \times 1 \mathrm{~min})$ and DCM $(5 \times 1$ min) using $10 \mathrm{~mL}$ of solvent per gram of resin for each wash. Coupling of amino acids 19-37 was carried out by adding the reagents $\mathrm{AA} / \mathrm{DIC} / \mathrm{OxymaPure}(0.3 \mathrm{M}$ solution) in a ratio of $3 / 3 / 3$ equiv and then shaking for $90 \mathrm{~min}$, unless stated otherwise. The resin was washed with DMF $(5 \times 1 \mathrm{~min})$ and $\operatorname{DCM}(5 \times 1 \mathrm{~min})$ after each coupling. Couplings were monitored by the ninhydrin test. Introduction of amino acids 8-18 (in their respective forms) was performed by using AA/ HCTU/DIEA ( 3 equiv) in 120 min couplings.

BAL Incorporation. The ChemMatrix resin $(0.6 \mathrm{~g})(f=$ $0.58 \mathrm{mmol} / \mathrm{g})$ was washed with DCM $(3 \times 3 \mathrm{~min})$. The BAL linker (6 equiv $560 \mathrm{mg}$ ) was then coupled onto the resin with DIC/OxymaPure (6 equiv $263 \mu \mathrm{L} / 296 \mathrm{mg}$ ) in DMF. The resin was then stirred for $4 \mathrm{~h}$, followed by filtering and washing with DMF $(5 \times 1 \mathrm{~min})$ and DCM $(5 \times 1 \mathrm{~min})$. The ninhydrin test was performed (negative), and the aldehyde test (positive) confirmed that the BAL linker had been effectively coupled.

Gly Addition by Reductive Amination. The resin was suspended in DMF and the free amine H-Gly-OtBu (10 equiv $579 \mathrm{mg}$ ) was added in the form of a solution in $1 \%(\mathrm{v} / \mathrm{v})$ $\mathrm{AcOH}$ in DMF (approx. $100 \mu \mathrm{L}$ of $\mathrm{AcOH}$ per gram of resin) for $30 \mathrm{~min}$ prior to the addition of a solution of $\mathrm{NaBH}_{3} \mathrm{CN}(10$ equiv $218 \mathrm{mg}, 300 \mathrm{mM}$ ) in $\mathrm{MeOH}$. The resin was shaken overnight. After that, the resin was washed with DMF $(5 \times 1$ $\mathrm{min})$ and $\mathrm{DCM}(5 \times 1 \mathrm{~min})$. The reaction was monitored by the aldehyde test (negative). ${ }^{29}$

First Arg Acylation. Fmoc-Arg(Pbf)-OH (3 equiv 677 $\mathrm{mg}$ ) was then coupled using DIC/OxymaPure (3 equiv 131 $\mu \mathrm{L} / 148 \mathrm{mg}$ ) in $45 \mathrm{~mL}$ of DMF as the coupling cocktail for 90 min. To ensure optimal amino acid incorporation, the coupling of Fmoc-Arg(Pbf)-OH was repeated overnight. After that, a sample of loaded resin was taken to test for proper incorporation by Fmoc determination. Finally, the Fmoc group was removed, and the ninhydrin test was performed (positive) prior to continuation of the peptide synthesis.

Use of Pseudoprolines. Some amino acids within the sequence can be introduced as pseudoprolines. This makes the synthesis faster and cleaner. However, these compounds are expensive and their use is discouraged. Nevertheless, the introduction of the first pseudoproline in the sequence is required to obtain good purity. If pseudoprolines are not used and DIC/Oxyma is the coupling cocktail, recouplings will become mandatory and, still, purity will be very low. If HCTU/DIEA are used as coupling reagents for amino acids 11-18 with no pseudoprolines, the product is obtained but with a large amount of impurities.

Fmoc Determination. An aliquot of loaded resin was washed with DMF $(3 \times 5 \mathrm{~mL})$ and $\mathrm{DCM}(3 \times 5 \mathrm{~mL})$. It was then dried under vacuum. The dried resin $(10 \mathrm{mg})$ was added to a $2 \mathrm{~mL}$ polypropylene tube, $0.8 \mathrm{~mL}$ of DMF was added, and the resin was allowed to swell for $10 \mathrm{~min}$. Then, $0.2 \mathrm{~mL}$ of piperidine was added and the mixture was shaken for $20 \mathrm{~min}$. Next, $10 \mu \mathrm{L}$ of the supernatant was pipetted into a cuvette and diluted with $0.990 \mathrm{~mL}$ of DMF. The absorbance at $301 \mathrm{~nm}$ was determined. The piperidine-dibenzofulvene adduct formed upon Fmoc deprotection had a $\varepsilon=7800 \mathrm{~L} / \mathrm{mol} / \mathrm{cm}$; thus, the loading value was determined using the Beer-Lambert law.

Fmoc Group Removal. (i) DMF $(5 \times 1 \mathrm{~min})$; (ii) piperidine/DMF $(2: 8)(1 \times 1 \mathrm{~min}+2 \times 10 \mathrm{~min})$; (iii) $\mathrm{DMF}$ $(5 \times 1 \mathrm{~min})$. 
Alloc Group Removal. (i) DCM $(5 \times 1 \mathrm{~min})$; (ii) $\mathrm{Pd}\left(\mathrm{PPh}_{3}\right)_{3} / \mathrm{PhSiH}(0.1: 10)(2 \times 10 \mathrm{~min}$ in $\mathrm{DCM})$; (iii) $\mathrm{DCM}$ $(5 \times 1 \mathrm{~min})$.

Palm Moiety Introduction. During the synthesis, $\mathrm{Lys}^{27}$ was introduced as Fmoc-Lys(Alloc)-OH. After removal of the Alloc group, the resin was treated with Palm-Glu( $(\mathrm{OSu})-\mathrm{O} t \mathrm{Bu}$ (5 equiv) and DIEA (10 equiv) in DCM for $16 \mathrm{~h}$.

Chloranil Test. ${ }^{25}$ A piece of resin (approx. $1 \mathrm{mg}$ ) was transferred to a small test tube, and $250 \mu \mathrm{L}$ of acetone was added. Then, $50 \mu \mathrm{L}$ of a saturated solution of chloranil was added. The tube was shaken for $5 \mathrm{~min}$ at room temperature. When free secondary amines are present, the beads turn a strong greenish/bluish color. In the case of primary amines, the beads become brown. No change in color is detected when there is no free amine.

Aldehyde Test. ${ }^{29} \mathrm{~A}$ few methanol-washed beads of the resin were placed into a small test tube. The test solution $(300$ $\mu \mathrm{L}$ ) was added, and the tube was heated at $110^{\circ} \mathrm{C}$ for $4 \mathrm{~min}$ (a blank control test using only the MBHA resin is advisable).

When no free $\mathrm{CHO}$ is present, the beads should be colorless, as is the blank. If color appears, $\mathrm{CHO}$ groups are present on the resin. The use of a microscope is recommended for low aldehyde content.

To prepare the test solution, ethanol $(88 \mathrm{~mL})$, sulfuric acid $(9 \mathrm{~mL})$, acetic acid $(1 \mathrm{~mL})$, and $p$-anisaldehyde $(2.55 \mathrm{~mL})$ were mixed, and the resulting solution was stored at $4{ }^{\circ} \mathrm{C}$. The solution can be kept for a few days, but the use of freshly prepared solution is advisable.

Cleavage. After the peptide backbone was finished, the peptidyl resin was washed with $\mathrm{DCM}(5 \times 1 \mathrm{~min})$ and $\mathrm{MeOH}$ $(5 \times 1 \mathrm{~min})$. Cleavage was carried out with $10 \mathrm{~mL}$ of a mixture of TFA/ $\mathrm{H}_{2} \mathrm{O} / \mathrm{TIS}$ (94:3:3) per gram of resin for $4 \mathrm{~h}$. After filtration, the resin was washed twice with the same mixture (5 $\mathrm{mL}$ ). The TFA solution was concentrated to one-third and triturated. The centrifuged solid was resolved in a solution of $3 \% \mathrm{AcOH}$ in $\mathrm{H}_{2} \mathrm{O}$ and lyophilized. HPLC trace showed that the crude purity of the product was $84 \%$ by HPLC (UV detection).

Purification. The crude unprotected liraglutide was purified by means of semipreparative RP-HPLC [Waters (Milford, MA) chromatography system using a Symmetry $C_{18}$ $\left(3 \times 10 \mathrm{~cm}^{2}, 5 \mu \mathrm{m}\right)$ column]. Starting conditions: $95 \% \mathrm{H}_{2} \mathrm{O}$ with $0.1 \%$ TFA (phase A) and $5 \%$ ACN with $0.1 \%$ TFA (phase $B)$. Gradient used: 3 min under starting conditions, then $1 \mathrm{~min}$ to $49 \%$ of B in A; after that, 5 min to $51.5 \%$ of B in A, rising to $100 \%$ of $B$ in $1 \mathrm{~min}$ and clean during 2 min before going back to the starting material. Liraglutide elutes around minute 7 of the gradient.

Liraglutide. Sequence. H-His-Ala-Glu-Gly-Thr-Phe-ThrSer-Asp-Val-Ser-Ser-Tyr-Leu-Glu-Gly-Gln-Ala-Ala-Lys(Palm)Glu-Phe-Ile-Ala-Trp-Leu-Val-Arg-Gly-Arg-Gly-OH.

The use of pseudoprolines was preferred for the amino acids indicated in bold to ensure the best purities. The amino acids indicated in italics were introduced using HCTU/DIEA. The rest of the amino acids were introduced by means of a DIC/ OxymaPure cocktail. Crude purity: $84 \%$ yield of synthesis after a preparative purification of $69 \%$.

Chemical Formula. $\mathrm{C}_{172} \mathrm{H}_{265} \mathrm{~N}_{43} \mathrm{O}_{51}$ expected MS of liraglutide: $3752.3(\mathrm{M}+\mathrm{H})$; found MS: $1876.6(\mathrm{M}+\mathrm{H})^{2+}$, $1251.5(\mathrm{M}+\mathrm{H})^{3+}, 938.9(\mathrm{M}+\mathrm{H})^{4+}$, and $751.2(\mathrm{M}+\mathrm{H})^{5+}$.

\section{ASSOCIATED CONTENT}

\section{(S) Supporting Information}

The Supporting Information is available free of charge on the ACS Publications website at DOI: 10.1021/acsomega.9b00974.

Sequence and synthetic scheme of liraglutide; MS and HPLC traces of liraglutide (PDF)

\section{AUTHOR INFORMATION}

\section{Corresponding Author}

*E-mail: albericio@ub.edu, albericio@ukzn.ac.za. Phone: (+34) 618089 145, (+27) 614009144.

\section{ORCID $\odot$}

Ayman El-Faham: 0000-0002-3951-2754

Fernando Albericio: 0000-0002-8946-0462

\section{Author Contributions}

The strategy was designed by all authors; the experiments were carried out mainly by D.C. All authors discussed the results and prepared the manuscript.

\section{Funding}

This work was funded in part by the following: Lonza AG (Visp, Switzerland), the Spanish Ministry of Economy, Industry and Competitiveness (MINECO) (CTQ201567870-P and RTC-2014-2207-1), CIBER-BBN and the Generalitat de Catalunya (2017 SGR 1439) (Spain), and the International Scientific Partnership Program ISPP at King Saud University (ISPP\# 0061) (Saudi Arabia).

Notes

The authors declare no competing financial interest.

\section{REFERENCES}

(1) de la Torre, B. G.; Albericio, F. The Pharmaceutical Industry in 2018. An Analysis of FDA Drug Approvals from the Perspective of Molecules. Molecules 2019, 24, 809.

(2) Zompra, A. A.; Galanis, A. S.; Werbitzky, O.; Albericio, F. Preparation of Peptides as Active Pharmaceutical Ingredients (API). Future Med. Chem. 2009, 1, 361-377.

(3) (a) Al Musaimi, O.; Al Shaer, D.; De la Torre, B. G.; Albericio, F. 2017 FDA Peptide Harvest. Pharmaceuticals 2018, 11, 42. (b) Al Shaer, D.; Al Musaimi, O.; Albericio, F.; De la Torre, B. G. 2018 FDA TIDES Harvest. Pharmaceuticals 2019, 12, 52.

(4) Merrifield, R. B. Solid Phase Peptide Synthesis. I. The Synthesis of a Tetrapeptide. J. Am. Chem. Soc. 1963, 85, 2149-2154.

(5) Felix, A. M.; Merrifield, R. B. Azide solid phase peptide synthesis. J. Am. Chem. Soc. 1970, 92, 1385-1391.

(6) Thieriet, N.; Guibé, F.; Albericio, F. Solid-Phase Peptide Synthesis in the Reverse $(N \rightarrow C)$ Direction. Org. Lett. 2000, 2, $1815-1817$

(7) Rink, H. Solid-phase synthesis of protected peptide fragments using a trialkoxy-diphenyl-methylester resin. Tetrahedron Lett. 1987, $28,3787-3790$

(8) Albericio, F.; Kneib-Cordonier, N.; Biancalana, S.; Gera, L.; Masada, R. I.; Hudson, D.; Barany, G. Preparation and application of the 5-(4-(9-fluorenylmethyloxycarbonyl)-aminomethyl-3,5-dimethoxyphenoxy)-valeric acid (PAL) handle for the solid-phase synthesis of C-terminal peptide amides under mild conditions. J. Org. Chem. 1990, 55, 3730-3743.

(9) Sieber, P. A new acid-labile anchor group for the solid-phase synthesis of C-terminal peptide amides by the Fmoc method. Tetrahedron Lett. 1987, 28, 2107-2110.

(10) Wang, S. S. p-Alkoxybenzyl Alcohol Resin and p-Alkoxybenzyloxycarbonylhydrazide Resin for Solid Phase Synthesis of Protected Peptide Fragments. J. Am. Chem. Soc. 1973, 95, 1328-1333. 
(11) Barlos, K.; Chatzi, O.; Gatos, D.; Stavropoulos, G. 2Chlorotrityl chloride resin. Studies on anchoring of Fmoc-aminio acids and peptide cleavage. Int. J. Pept. Protein Res. 1991, 37, 513520.

(12) Cherkupally, P.; Acosta, G. A.; Nieto-Rodriguez, L.; Spengler, J.; Rodriguez, H.; Khattab, S. N.; El-Faham, A.; Shamis, M.; Luxembourg, Y.; Prohens, R.; Subiros-Funosas, R.; Albericio, F. KOxyma: a strong acylation-promoting, 2-CTC resin-friendly coupling additive. Eur. J. Org. Chem. 2013, 6372-6378.

(13) Albericio, F.; Barany, G. Improved approach for anchoring $N^{\alpha}$ 9-fluorenylmethyolxycarbonylamino acids as $p$-alkoxybenzyl esters in solid-phase peptide synthesis. Int. J. Pept. Protein Res. 1985, 26, $92-$ 97.

(14) Rovero, P.; Vigano, S.; Pegoraro, S.; Quartara, L. Synthesis of the bradykinin B1 antagonist [desArg10]HOE 140 on 2-chlorotrityl resin. Lett. Pept. Sci. 1996, 2, 319-323.

(15) Albericio, F.; van Abel, R.; Barany, G. Solid-phase synthesis of peptides with C-terminal asparagine or glutamine. Int. J. Pept. Protein Res. 1990, 35, 284-286.

(16) Alsina, J.; Rabanal, F.; Giralt, E.; Albericio, F. Solid-phase synthesis of head-to-tail cyclic peptides via lysine side-chain anchoring. Tetrahedron Lett. 1994, 35, 9633-9636.

(17) Kaspari, A.; Schierhorn, A.; Schutkowski, M. Solid-phase synthesis of peptide-4-nitroanilides. Int. J. Pept. Protein Res. 1996, 48, 486-494.

(18) (a) Jensen, K. J.; Alsina, J.; Songster, M. F.; Wagner, J.; Albericio, F.; Barany, G. Backbone Amide Linker (BAL) Strategy for Solid-Phase Synthesis of C-Terminal-Modified and Cyclic Peptides. J. Am. Chem. Soc. 1998, 120, 5441-5452. (b) Guillaumie, F.; Kappel, J. C.; Kelly, N. M.; Barany, G.; Jensen, K. J. Solid-phase synthesis of Cterminal peptide aldehydes from amino acetals anchored to a backbone amide linker (BAL) handle. Tetrahedron Lett. 2000, 41, 6131-6135. (c) Royo, M.; Farrera-Sinfreu, J.; Solé, L.; Albericio, F. Four-dimensional orthogonal solid-phase synthesis of new scaffolds based on cyclic tetra- $\beta$-peptides. Tetrahedron Lett. 2002, 43, 20292032.

(19) Paradís-Bas, M.; Tulla-Puche, J.; Albericio, F. The road to the synthesis of "difficult peptides". Chem. Soc. Rev. 2016, 45, 631-654.

(20) (a) Wöhr, T.; Wahl, F.; Nefzi, A.; Rohwedder, B.; Sato, T.; Sun, X.; Mutter, M. Pseudo-Prolines as a Solubilizing, Structure-Disrupting Protection Technique in Peptide Synthesis. J. Am. Chem. Soc. 1996, 118, 9218-9227. (b) Keller, M.; Sager, C.; Dumy, P.; Schutkowski, M.; Fischer, G. S.; Mutter, M. Enhancing the Proline Effect: PseudoProlines for Tailoring Cis/Trans Isomerization. J. Am. Chem. Soc. 1998, 120, 2714-2720.

(21) https://www.drugs.com/victoza.html.

(22) Bray, B. L. Large-scale manufacture of peptide therapeutics by chemical synthesis. Nat. Rev. Drug Discovery 2003, 2, 587-593.

(23) Recently, our group has published a strategy for the synthesis of C-protected peptides compatible with the hybrid/convergent approach using liraglutide as model. Carbajo, D.; Fransen, P.; ElFaham, A.; Royo, M.; Albericio, F. Pseudo-Wang Handle for the Preparation of Fully Protected Peptides. Synthesis of Liraglutide by Fragment Condensation. Org. Lett. 2019, 21, 2459-2463.

(24) (a) García-Martín, F.; Quintanar-Audelo, M.; García-Ramos, Y.; Cruz, L. J.; Gravel, C.; Furic, R.; Côté, S.; Tulla-Puche, J.; Albericio, F. ChemMatrix, a Polyethylene glycol (PEG)-based Support for the Solid-Phase Synthesis of Complex Peptides. J. Comb. Chem. 2006, 8, 213-220. (b) Frutos, S.; Tulla-Puche, J.; Albericio, F.; Giralt, E. Chemical Synthesis of ${ }^{19}$ F-labeled HIV-1 Protease using Fmoc-Chemistry and ChemMatrix Resin. Int. J. Pept. Res. Ther. 2007, 13, 221-230. (c) Subiros-Funosas, R.; Acosta, G. A.; El-Faham, A.; Albericio, F. Microwave irradiation and COMU: a potent combination for solid-phase peptide synthesis. Tetrahedron Lett. 2009, 50, 6200-6208. (d) Bacsa, B.; Bösze, S.; Kappe, C. O. Direct Solid-Phase Synthesis of the $\beta$-Amyloid (1-42) Peptide Using Controlled Microwave Heating. J. Org. Chem. 2010, 75, 2103-2106. (e) García-Ramos, Y.; Paradís-Bas, M.; Tulla-Puche, J.; Albericio, F.
ChemMatrix for complex peptides and combinatorial chemistry. $J$. Pept. Sci. 2010, 16, 675-678.

(25) Christensen, T.; Eriksson, A.; Thornell, L.-E. A Qualitative Test for Monitoring Coupling Completeness in Solid Phase Peptide Synthesis Using Chloranil. Acta Chem. Scand. 1979, 33b, 763-766.

(26) Kaiser, E.; Colescott, R. L.; Bossinger, C. D.; Cook, P. I. Color test for detection of free terminal amino groups in the solid-phase synthesis of peptides. Anal. Biochem. 1970, 34, 595-598.

(27) Farrera-Sinfreu, J.; Royo, M.; Albericio, F. Undesired removal of the Fmoc group by the free $\varepsilon$-amino function of a lysine residue. Tetrahedron Lett. 2002, 43, 7813-7815.

(28) The preparation of the liraglutide using this strategy has protected by the patent: Carbajo Lopez, D.; Albericio Palomera, F. Method for preparation of liraglutide using BAL linker. PCT Int. Appl., WO2017138855A1, 2017.

(29) Vázquez, J.; Albericio, F. A useful and sensitive color test to monitor aldehydes on solid-phase. Tetrahedron Lett. 2001, 42, 66916693. 